\title{
Convenience and Medical Patient Database Benefits and Elasticity for Accessibility Therapy in Different Locations
}

\author{
Bambang Eka Purnama \\ Faculty of Informatics Engineering \\ Surakarta University, Surakarta, Indonesia
}

\author{
Sri Hartati \\ Faculty of Mathematics and Natural Science \\ University of Gadjah Mada Yogyakarta, Indonesia
}

\begin{abstract}
When a patient comes to a hospital, clinic, physician practices or other clinics, the enrollment section will ask whether the patient in question had never come or not. If the patient in question said he had never come then the officer will ask you Medication Patient Identification Card (KiB), which will be used to search for patient records in question. In the conventional health care, then the officer will use a tracer to locate patient records at the storage warehouse in the form of stacks of paper. If a patient at a hospital is still a bit it will not be problematic, but if the patient sudha achieve large-scale number in the hundreds of thousands or even millions it will certainly cause problems.

Database records are kept in hospital untapped to the maximum to be exchanged at another hospital when the patient arrives at another hospital for further treatment or research purposes. This study aims to produce a computerized model of inter Medical Information Systems Hospital. Facilitate the benefits of this research is in the medical records of patients get information, patient history properly stored in computerized medical records, patient data search can be found quicker resulting in faster unhandled The expected outcome of this research is rapidly tertanganinya patients coming to a clinic and when the patient comes to the clinic to another place then the patient's medical resume database and the analysis can be found immediately.
\end{abstract}

Keywords- Patient Medical Record.

\section{BACKGROUND PROBLEM}

Medical Record management activities will produce data and information in the form of indicators to be used as the evaluation of hospital services. Medical record service system goal is to provide information to facilitate management of the service to patients and facilitate managerial decision-making by the provider of clinical and administrative health care facilities. Therefore we need good data management RM start of input, process and output.

But the RM data management activities are currently running there are still some problems that the patient data input, written by officers in TPPRJ not complete, the process (data management still done conventionally) and output (reports / information only in the form of the ratio of old and new patient visits, the ratio of patient visits and specialists poly) so that the evaluation activities undertaken by service managers in particular to determine the productivity of outpatient services to be obstructed.
Hospital Information System should be able to contribute to all activities of the hospital management. Management information system of a hospital not only serve the statistical data requirements alone but should be able to generate useful information for medical decision-making process. In addition to the medical record contains information about all patients who had been treated, it can also be used as a reference when the patient was treated again. Health workers will be difficult to take action if not yet know the history or the history of the patient's disease before the action is recorded in the previous medical record file. One other important matters contained in the medical record file is the availability and completeness of its contents when needed.

As an initial illustration, there is a case study conducted by Clarke toxicology section, hospital, Edinburgh, UK that is usually used for inpatient services. The main function of the toxicology section is to provide medical care. In practice there is often confusion between the team of physicians and delivery of health services to patients. A patient should be placed in service where and treated by a doctor who? The problem is long and difficult quest to collect patient data is fragmented. Telephone and the conversation became a fact of discussion and exchange of information to get the conclusion of patient care. But after using EMR, EMR servants saw enough to get the patient's medical summary and decided conclusion. Prihartono (2008)

Electronic Medical Records are required to provide webbased system, easy to use and requires no investment in costly infrastructure and resources. The system is also required to have electronic prescriptions, receiving lab results electronically, using a structured data and nomenclature are given by the SNOMED (Systematized Nomenclature of Medicine), NDC (National Drug Code), or other data for documentation and have the ability to generate clinical data , administrative and demographic reports. Gates and Roeder (2011)

Electronic Medical Record is widely used in various hospitals in different parts of the world to replace or complement the medical record file form. Since the development of e-Health, EMR is at the heart of information from hospital information systems. Prihartono (2008) Electronic Medical Records (EMRs) is a computerized medical information system that collects, stores and displays 
patient information. It is a means to create a legible and terorganisirnya records and access to clinical information about patients. Furthermore EMRs are intended to replace the existing system (often paper-based) medical records which are familiar to practitioners. Patient records have been kept in paper form in a long time, they had consumed the greater space and delaying access to medical care becomes less efficient. In contrast, EMRs storing individual patient clinical information electronically and allows instant availability of this information to all providers in the chain of health and assist in providing a coherent and consistent care. Although expectations are high and interest in EMRs across the world, their overall adoption rate is relatively low and facing some problems. For example, employment is deemed contrary to the traditional style of a doctor, they need a greater ability in handling the computer and install a system that absorbs sufficient financial resources. Boonstra and Broekhuis (2010)

With the EHR enables the implementation of an increasingly complex cross-communication among health professionals with various parties who are both providing care for patients in health care facilities, EHR can also be used as one important input in assessing the success of health programs at institutions of existing services. (Minister of Health RI, 2005).

A clinical information system is a collection of various information technology applications that provide a centralized repository of information related to patient care across distributed locations. This repository is the patient's disease history and interactions with coding knowledge provider that can help doctors decide on the patient's condition, treatment options and medical procedures. The Repository also encodes status decisions, actions taken to decision-making and relevant information that can help in performing the act. The database can also store information about patients, including genetic, environmental and social context. Sittig et al (2002)

Leading health organizations have emphasized the importance of integrating information technology into the healthcare system to improve provider practices, improve the quality of patient care and reduce medical errors. One of the problems that interfere with the spread of technology into health care is how to combine the practical, clinical information systems can be used in the work environment of providers. Alexander (2008)

Electronic Medical Record technology allows medical providers to store and exchange medical information using a computer. Although the technology has been available since the 1970s, only 50\% of hospitals are adopting the basic EMR system in 2005. Slow diffusion of EHR that has attracted attention, since the adoption of EMR could reduce U.S. \$ $1,900,000,000,000$ annual U.S. health care bill through increased efficiency and comfort. Although some hospitals adopted EMR necessary for the transfer of electronic information, but also must cooperate and coordinate cross hospital. In 2006 an eHealth Initiative survey (Covich Bordenick, Marchibroda and Welebob (2006)) identified more than 165 active Health Information Exchange initiatives in the U.S., 45 are being implemented and 26 are fully operational. Miller and Tucker (2007)
Data warehouse modeling method has been used in the industry standard for years for decision support in various fields. Data warehouse design for healthcare industry outside well understood and has been widely discussed. Healthcare is still far behind, in the field of data warehouse management, decision support and the need to move forward in this direction. Parmanto et al (2005)

With the awareness of medical errors and increase the focus on improving the quality of patient care, President George W. Bush (American President Currently it is) called for electronic health records for all Americans by 2014. Latest figures estimate the adoption of EHR in the outpatient environment to $13 \%$ for the base system and $4 \%$ only for a fully functional EHR system. It also includes penalties for providers who fail to adopt. Morton et al (2009)

Program to introduce an electronic medical record that enables the sharing of health information between sites is being conducted in many developed countries including Australia, Canada, Denmark, England, Finland, France, New Zealand and the United States. The information is uploaded records the patient's identity, CHI number (unique patient identifier in Scotland), and the prescription drug reactions or allergies. All patients have the information that is uploaded to a central database 2 times a day unless they have actively opted out of the system. Health professionals who want to access information in the ECS is expected to obtain consent of the patient at the time of contact (unless the patient is unconscious). Johnstone and McCartney (2010)

Health Level Seven (HL7) is a standard for electronic exchange of patient medical record information is supported by the National Committee on Vital and Health Statistics (NCVHS). HL7 standards developed by bodies accredited by the American National Standards Institute. This is a message standard that allows software applications to exchange information across platforms in a way to protect the meaning of the information submitted. Gudea (2005)

\section{MEDICAL RECORD}

In the explanation of Article 46 paragraph (1) Medical Practice Act, which is a medical record is a file containing records and documents about the identity of thepatient, examination, treatment, action, and other services provided to patients. In the Minister of Health of the Medical Record Number 749a / Menkes / Per / XII / 1989 explained that the medical record is a file containing records and documents about the identity of the patient, examination, treatment, action, and other services to patients in healthcare facilities.

\section{ELECTRONIC MEDICAL RECORD}

Electronic Medical Record (EMR) is the lifetime of the patient medical records in electronic format and can be accessed by computer from a network with the main purpose to provide or improve care and health services in an efficient and integrated. EMR become a key strategy of integrated health services at various hospitals. Prihartono (2008) 


\section{BENEFITS OF MEDICAL RECORDS}

a. Treatment of Patients. Medical records serve as the basis and guidance to plan and analyze the disease and plan treatment, care and treatment to be given to the patient.

b. Improving the Quality of Service. Creating Medical Record for the organization of medical practice with a clear and complete information will improve the quality of care to protect medical personnel and the achievement of optimal health.

c. Education and Research. Medical record is the chronological progression of disease information, medical services, treatments and medical procedures, useful for the development of information materials for teaching and research in the field of medical and dental professions.

d. Financing. Medical record file can be used as guidance and materials to establish the financing of health services at health facilities. Notes can be used as proof of financing to the patient.

e. Health Statistics. Medical records can be used as health statistics, especially for studying the development of public health and to determine the number of patients on specific diseases.

f. Problems of Proof Law, Discipline and Ethics. Medical record is the main written evidence, making it useful in the resolution of legal issues, discipline and ethics.

\section{STUDY REFERENCES}

According Hosizah explained that implementation of the hospital Medical Records Indonesia started in 1989 in line with the Regulation of Minister of Health Affairs Medical Record, which includes the setting is still paper-based medical records (conventional). Conventional medical record is considered no longer appropriate for use in the 21 st century the use of information-intensive and environment-oriented automation and health care is not solely focused on the work unit. Currently in Indonesia there were approximately 1300 hospitals and thousands of health centers (Menkes RI) that the government would need to think about the design of the parent (grand design) EHR strategically arranged by region includes eastern Indonesia, Central and West.

According Prihartono (2008) From Clarke writing a case study that the effects of EMR technology implementation is often unpredictable and can only be determined by using it. To be successful applied technology such as EMR, theory and practice must be balanced. So we need a test EMR. Janz and Brian Hennington test the adoption of EMR by physicians with the model Unified Theory of Acceptance and Use of Technology (UTAUT). By doing a literature study of the implementation of the UTAUT Model year 2000 - 2007, Hennington concluded that the factors influencing the decision-making EMR adoption: uncertainty on investment turnover EMR, EMR integration with existing business processes before, the potential of EMR to improve quality of care, convenience of use EMR, the amount of effort to change the workflow to fit the use of EMR, as well as funding availability and duration of adaptation. EMR adoption by a hospital, is also influenced by the local law of privacy and the use of EMR by the trend of other hospitals. Miller and Tucker empirically using a variation in the privacy of local law. The result indicates a positive network effect in the spread of EMR. There are five variables used to help predict the decision for pushing hospitals to adopt EMR, namely:

a. InstalledHSA: number of hospitals are adopting EMR in a year

b. HospPrivLaw: Indicators of privacy laws

c. HospPrivLaw * InstalledHSA: results of a variable time before

d. Xit: hospital characteristics and state

e. Eit: Error stochastic

All of the data to a formula derived from the data base of 2005 issued by the "Healthcare Information and Management Systems Society. HIMSS database covers most of the hospitals in the United States. The author gets the data as much as 4010 the hospital. 1937 hospitals have adopted EMR. 3988 the hospital's decision to adopt a system of "enterprisewide EMR".

Two researchers from Malaysia, Mohd and Mohamad, forming a model of acceptance of EMR in the form of the questionnaire survey, particularly for the major hospitals in Malaysia. The core of their model is the incorporation of the Technology Acceptance Model (TAM) with User Interface Interaction Satisfaction Questionnaire (Marquis). By combining the TAM and the Marquis, as well as several other models of theories, then obtained a receipt of the appropriate models to evaluate the EMR.

According Handoyo et al (2008), are presented in this paper that in order to build theHospital Information System is the most efficient use of the Prado due Framework

According Arianto in his paper entitled Open PlatformBased Applications Programming Xml Web Services (Case Study: Collaboration Applications and Data Exchange of the Population With Medical Records). It is said that the population data can be used to mensuport patient data at a hospital. In the presented architecture is one solution for distributed computing applications in a cluster collaboration and data exchange. Architecture described in his presentation.

According Setyanto in his paper entitled Mobile Medical Records said that the medical records of mobile applications will make double the storage of medical records. Medical records will be stored on the server where the hospital treated patients and in patients of coffee in the mobile device. Double the storage is done so that when the required medical records of patients at other hospitals where new patients never treated, the new hospital can retrieve data from the patient's pertinent medical records without the need to deal with patients from the hospital. The addition of medical records at the time of treatment of transactions to be recorded back into the patient's mobile device. In this way the medical records contained in the mobile device will be the most complete data. To enable the synchronization with the data at the beginning of the hospital if the patient wants a new backup data as well as his medical records to synchronize the applications that are embedded in the mobile device will synchronize with the hospital system from which he recorded via web services service owned hospitals. This feature can be designed 
automatically when a signal is a data communications network.

Doctors will be helped in doing the best treatment decisions for patients. Patients will benefit from the certainty of the data unreadable medical history and basis for treatment decisions for themselves. Government and health researchers will get an abundance of data is ready if that research could be done more easily and the data is more complete. Strategic decisions taken by the government can also better because of the completeness of data. Mobile data communication service providers also benefit from the increased traffic that is not only extended service mobile banking, but possess the new land mobile medic.

According to Boonstra and Broekhuis (2010) explained that the implementation of Electronic Medical Records, Financial constraints become a major factor. Monetary aspect is an important factor for many physicians. Common questions faced by clinicians is whether the costs of implementing and running an affordable EMR system and whether they can benefit financially from it. The cost of EMR can be divided into two, namely the initial cost and ongoing costs, monitoring, upgrades, and administration costs. Their surveys, have concluded that the physician has adequate technical knowledge and skills to deal with EMRs. Meade et al observed in a context that most of the current generation of doctors in Ireland to receive their qualifications before the IT program was introduced.

According to Desroches et al in his paper entitled Use of Electronic Health Records in U.S. Hospitals. Conduct a survey using the methods surveyed all acute care hospitals that are members of the American Hospital Association to the presence of the specific functions of electronic records. Using the definition of electronic health records based on expert consensus, to determine the proportion of hospitals that have such systems in their clinical areas. Also examined the relationship of adoption of electronic health records with certain hospital characteristics and the factors that are reported to be barriers or facilitators of adoption.

From a survey based on responses from $63.1 \%$ of surveyed hospitals, only $1.5 \%$ of U.S. hospitals have comprehensive electronic records system that is in all clinical units and an additional $7.6 \%$ have basic systems in which at least one clinical unit . Computerized provider order for the drug has been applied to $17 \%$ of the hospital. Larger hospitals located in urban and teaching hospitals were more likely to have an electronic records system. Respondents cited capital requirements and high maintenance costs as the main barriers to implementation, although hospitals with electronic records systems were less likely to mention the constraints of a hospital without such a system. AK Jha concluded his research is a very low level of adoption of electronic health records in U.S. hospitals suggest that policymakers face major obstacles to the achievement of healthcare performance goals that depend on health information technology.

Raisinghani and Young put his research, entitled Personal health records: key adoption issues and implications for management. Presented that Electronic Personal Health (PHRs) have been considered as a tool to empower consumers to become active decision makers about their health, instead of leaving the decision to the provider. Paper-based health systems and fragmented is no longer suitable for the digital economy in the 21 st century. Integrated health information technology system is the solution to change clinical practice to consumer centric and information. Tools such as PHRs are a means to achieve goals that provide better health, safer and more affordable for consumers. However, there has been little research done to show the real value of PHR, although widely perceived value of this technology. Although survey data indicate that there is a lack of awareness among the public, consumers accept this concept, especially when the doctor recommends it.

Zaroukian and Sierra in his paper benefiting from ambulatory EHR implementation: solidarity, six sigma, and willingness to strive. Explained that the system of electronic ambulatory health records has the potential to improve the quality of healthcare. Optimizing the value of EHR implementation requires that providers and staff to be effective and efficient EHR users so that the graph paper is no longer needed or desired. Transition from paper charts to EHR systems require changes in new learning. This case study describes how the EHR implementation of timely and routine use in a large medical clinic. Observed benefits include improved patient access, workflow efficiency, communication, use of decision support, and financial performance. These success factors and implementation strategies can help others trying to encourage greater adoption and use of EHRs.

Balfour et al in his paper entitled Health Information Technology presented the United States have been slow to use HIT. However, a variety of factors including increased government involvement, which accelerate the implementation and use of HIT. E-prescribing and EHR both electronic means to provide better coordination of care by allowing the various health care professionals to access patient medical records. Adoption of e-prescribing can reduce medication errors due to bad handwriting. Unfortunately, barriers to implementing eprescribing and EHR is still there, including resistance to learning new technologies, the initial start-up costs, delays in seeing a return on investment, lack of standard platforms, increasing the administrative burden and incentive alignment.

Shekelle et al in the paper Costs and benefits of health information technology to take the source data from PubMed, Cochrane Controlled Clinical Trials Register and Cochrane Database purpose Effectiveness Reviews (DARE) is an electronic search for articles published since 1995. Some of the reports prepared by private industry were also reviewed. Using the method of the 855 studies screened, 256 were included in the final analysis.

The results of 256 studies, 156 concerned decision support, electronic medical records of 84 and 30 about to be computerized physician entry (categories are not mutually exclusive). 124 of the studies assessing the effects of HIT systems in outpatient settings or outpatient; 82 assessed its use in the hospital setting or hospitalization. The ability of Electronic Health Records (EHRs) to improve the quality of care in ambulatory care facilities is shown in a small series of studies conducted at four sites (three U.S. medical centers and 
one in the Netherlands). HIT has the potential to enable a dramatic transformation in the delivery of health care, making it safer, more effective and more efficient.

Gagnon et al, Interventions for promoting information and communication technologies adoption in healthcare professionals. Exposure produces 10 studies met the inclusion criteria.. Use of the Internet for audit and feedback, and email to the provider-patient communication, were targeted in two studies. Their conclusion is very limited evidence on effective interventions to promote the adoption of ICT by health professionals. Small effects have been reported for interventions targeting the use of electronic databases and digital libraries. Effectiveness of interventions to promote the adoption of ICT in healthcare settings is still uncertain, and further trials are designed with both needed.

Morton et al (2009) concluded EHR has been developed over nearly three decades, yet some providers to realize an integrated electronic health records. Recent figures estimate 3$8 \%$ of EHR adoption in ambulatory care settings to $13 \%$ for the base system and $4 \%$ only for a fully functional EHR system. Patients seemed to accept that their physicians have computerized records secure and confidential, but they are increasingly unhappy with the safety record is held centrally. The concern is that the data may be used inappropriately by the government or may be hijacked. The risk increases with the number of illegal access data stored in a single repository (honeypot effect).

Pusic et al (2004) presented to exploit the opportunities for this type of clinical decision support interventions then it must have an effective health information systems. While electronic health records and databases to help physicians manage information, patient-specific recommendations provided by the clinical decision support systems can do more to improve decision making and help ensure patient safety. Computer technology can help to generate suggestions for specific cases of clinical decision making. The system used is usually referred to as clinical decision support systems. computerization can help make this valuable investment with a safer, more efficient and more effective health care. It is imperative that physicians involved in the development and rigorous scientific evaluation of this system.

Skouroliakou et al (2008) describes use of computerized hospital records could potentially reduce medical errors and improve the cost effectiveness of care by revealing the relationship between the severity of illness and resource consumption in the ICU setting. The importance of computerized data management to improve the safety and efficacy in the ICU for premature neonates has been fully realized for several decades. Availability of this information is enabling physicians to minimize the errors and re-evaluate current clinical practice.

Abdrbo et al (2011) described information systems can facilitate communication between nurses, doctors and other health team members and improve patient outcomes. In addition, the use of IS will ensure the completeness of documentation of patient care, facilitating the evaluation of the results of patient care and improve patient safety.
Parmanto et al (2005) presented to achieve national interoperability and realizing benefits, physician adoption rate should be increased substantially. However, implementing the right systems the right way is essential to ensure the success of the project and protect patient safety. Nearly $75 \%$ of all the major health information technology projects fail. Understanding of the factors associated with the acceptance of physicians' will enable organizations to better assess the readiness of the system and facilitate a successful implementation.

Johnstone and McCartney (2010) presented patients seem to accept that their physicians have a safe and confidential computerized records, but they are increasingly unhappy with the holding of centralized security record. The concern is that the data may be used inappropriately by the government or may be hijacked. The risk increases with the number of illegal access data stored in a single repository (honeypot effect).

Skouroliakou et al in an article entitled Data Analysis of the Benefits of an Electronic Registry of Information in a Neonatal Intensive Care Unit in Greece explained that the electronic documentation of several procedures for neonates, such as parenteral nutrition in the ICU, has been referred to in the literature. Establishment of monitoring systems allow for the research results as well as for the management of information. Availability of this information is enabling physicians to minimize the errors and re-evaluate current clinical practice. Over the last two years of a software program that combines rapid report generation and capacity for simple statistical analysis was developed and used for collecting, storing, and analyzing the data of newborns treated in intensive care unit three levels of Lito Maternity Hospital.

Et al in his paper Abdrbo Development and Testing of a Survey Instrument to Measure Benefits of a Nursing Information System, Health Information Management concluded benefits associated with quality of care using the System Information is associated with improved accessibility, accuracy and completeness of patient information that increases the effectiveness of nursing care . Nauright and Simpson12 reported high reliability (Cronbach alpha $=.94$ ) for quality-of-care items included in the questionnaire they used in their study of 697 nurses and staff of public hospitals.

Survey conducted by Hussein et al (2011) of 80 patients as responders were randomized at Bandung in January-May 2011. About $70 \%$ of respondents (56 people) were aged $18-50$ years, while $30 \%$ of respondents ( 24 people) were aged or under 9-17 years following table Generate

\begin{tabular}{|c|c|c|c|}
\hline No & Question & $\mathbf{Y}$ & $\mathbf{N}$ \\
\hline 1 & Understand the medical record in general & $90 \%$ & $10 \%$ \\
\hline 2 & $\begin{array}{l}\text { Knowing the long-term goal of the medical } \\
\text { record }\end{array}$ & $70 \%$ & $30 \%$ \\
\hline 3 & $\begin{array}{l}\text { Knowing the content rather than medical } \\
\text { record }\end{array}$ & $80 \%$ & $20 \%$ \\
\hline 4 & $\begin{array}{l}\text { Registered in more than one hospital in } \\
\text { Bandung }\end{array}$ & $99 \%$ & $1 \%$ \\
\hline 5 & $\begin{array}{l}\text { Percent came to the medical is about } 1 \text { times / } \\
\text { month or more }\end{array}$ & $80 \%$ & $20 \%$ \\
\hline 6 & Been admitted to hospital & $60 \%$ & $40 \%$ \\
\hline 7 & $\begin{array}{l}\text { Ever have one of the actions by the medical } \\
\text { officer }\end{array}$ & $50 \%$ & $50 \%$ \\
\hline
\end{tabular}




\begin{tabular}{|c|l|c|c|}
\hline 8 & $\begin{array}{l}\text { Given 60\% more on medical services } \\
\text { who had obtained }\end{array}$ & $20 \%$ & $80 \%$ \\
\hline 9 & $\begin{array}{l}\text { Given 60\% more on drugs that have } \\
\text { consumed the prescription / doctor action }\end{array}$ & $10 \%$ & $90 \%$ \\
\hline 10 & $\begin{array}{l}\text { Given 60\% more hospital ever } \\
\text { provide medical services }\end{array}$ & $80 \%$ & $20 \%$ \\
\hline
\end{tabular}

Based on the above table it can be concluded that patients rarely remember who had obtained medical services from childhood to the present, patients given the drug also rarely ever consumed from childhood to the present, when the average to obtain medical services once a month and is registered in more from one hospital. Thus the need for a complete documentation of the patient's health, correct and up to date that can provide health information to patients and medical personnel in times of need. Also needed the flexibility to read and access information by the patient's health is concerned. A total of 40 respondents had experienced any of the actions by medical personnel. The interviews explained that the medical officers often make mistakes because the action does not 'know' the patient at hand, that does not hold a valid and complete information regarding the patient's personal health information, not even knowing the patient's medical history at hand. The result is a medical tort (malpractice) so that patients suffering from trauma, fainting, itching rash, should be treated intensively, even resulting in loss of life.

Development of the National Medical Record System Web-based, so that medical record information can be accessed freely by the patient and medical personnel wherever the patient is or requires medical treatment. Web technologies into one technology that is widely used today because of the ability to meet the needs of web users are mobile .. Due to the web-based system, then both patients and medical personnel have access rights to different medical record. For example, the patient has a right to see medical records and medical history, while the doctor has the right to record into the patient's medical record is examined. The hospital is the party who first made the patient medical record (if the patient has not had a medical record), after the patient's medical record form the physician and / or other hospital staff can record the medical treatment and see pasian medical record, if needed. National web-based medical record can be accessed by the patient's mobile, so that patients can learn about personal health, knowing his medical history, and the patient can decide to choose a doctor or hospital that is suitable based on medical records. Know yourself is important, so are familiar with our own personal health, hospital and medical staff of data.

Implementation and Maintenance of Web-based Medical Record System to build Portal Center is administered by the Department of Health, Handling security using username and password plated, Maintenance of data by backing up your data based on a specific time period.

Every user has different levels of access rights to maintain the validity of the data. Normal development of databases that can make a good implementation of the system. Server support 24 hours to make the availability of patient health information for patients and physicians. Simple interface but achieve the delivery of information.

\section{DISCUSSION}

Physician practice conditions, hospital treatment and Hall are still many who use handwritten notes on paper to write medical records. That is not good, but in a previous study found many weaknesses. Various studies have previously shown that a lot of paper medical records led to the wrong perception because the article misspelled the difficult doctor read by other paramedics. Because medical records are poor or non-existent making it difficult to trace the history of the patient before the doctor who caused the worng diagnoiswill allow the caused the wrong diagnosis that will allow the mall practice. Electronic Medical Record technology allows medical providers to storeand mempertukaran medical information using a computer instead of paper. Different metadata systems in hospitals and other clinics should be made uniform by the authorities to enable the synchronization of data and can be utilized to the maximum.

Web portal development database of medical records are appropriately built in Indonesia which was shaded by the relevant departments of the ministries of health should require hospitals to build a database that is connected to the portal. Access password is not enough to use, it must use additional authentication, can be a barcode or fingerprint. Thus there is no one else can enter into the system unless the patient is concerned even if the user id and password not remembered.

\section{CONCLUSION}

a. Indonesia has not been widely applied in electronic medical records so that there are many drawbacks

b. Medical Record Information system is built in standard among hospitals and clinics will provide benefits of convenience and carrying medical resume so that patients can be misdiagnosed and press the number mall practice

\section{ADVICE}

Leadership of hospitals and clinics need to think logically and humbled to be willing to apply the patient's medical record system

\section{REFFERENCE}

[1] Amalia R. Miller_ and Catherine E. Tucker, (2007), Privacy Protection and Technology Diffusion: The Case of Electronic Medical Records, MIT Sloan School of Business, MIT, Cambridge

[2] Gagnon MP, Légaré F, Labrecque M, Frémont P, Pluye P, Gagnon J, Car J, Pagliari C, Desmartis M, Turcot L, Gravel K (2009) Interventions for promoting information and communication technologies adoption in healthcare professionals. Faculty of Nursing, Université Laval - Centre hospitalier universitaire de Q Canada

[3] Shekelle PG, Morton SC, Keeler EB. (2006), Costs and benefits of health information technology, Evid Rep Technol Assess

[4] Balfour DC 3rd, Evans S, Januska J, Lee HY, Lewis SJ, Nolan SR, Noga M, Stemple C, Thapar K, (2009), Health information technology, Sharp Rees-Stealy Medical Group, San Diego, California, J Manag Care Pharm.

[5] Zaroukian MH, Sierra A. (2006), Benefiting from ambulatory EHR implementation: solidarity, six sigma, and willingness to strive. J Healthc Inf Manag,.20(1):53-60.

[6] Raisinghani MS, Young E. Personal health records: key adoption issues and implications for management. School of Management, P.O. Box 425738, CFO 405, Denton, TX 76204-5738, USA. 
[7] Jha AK, Desroches CM, Campbell EG, Donelan K, Rao SR, Ferris TG, Shields A, Rosenbaum S, Blumenthal D, (2009), Use of Electronic Health Records in U.S. Hospitals. Citations selected from a literature search of the following database sources: PubMed, Web of Science, and CINHAL

[8] Albert Boonstra, Manda Broekhuis, (2010), Barriers to the acceptance of electronic medical records by physicians from systematic review to taxonomy and interventions, Boonstra and Broekhuis BMC Health Services Research

[9] K.M. Clarke, M. Rouncefield, M.J. Hartswood, R.N. Procter. (2001), The Electronic Medical Record And Everyday Medical Work. Health Informatics Journal, Vol. 7, No. 3-4, p. 168-170, SAGE

[10] Iwan Prihartono, (2008), Adopsi Rekam Medis Elektronik, Fakultas Ilmu Komputer, Universitas Indonesia,

[11] Edwin Yaqub, MSc, and Andre Barroso, PhD, (2010), Distributed Guidelines (DiG): A Software Framework for Extending Automated Health Decision Support to the General Population_2, Health Information Management, 1-15

[12] By Dean F Sittig, PhD; Brian L Hazlehurst, PhD; Ted Palen, MD, PhD; John Hsu, MD; Holly Jimison, PhD; Mark C Hornbrook, PhD, (2002), A Clinical Information System Research Landscape, The Permanente Journal, Volume 6 No. 2

[13] Gregory L. Alexander, PhD, RN, (2008), A Descriptive Analysis of a Nursing Home Clinical Information System with Decision Support, Perspectives in Health Information Management 5; 12

[14] Bambang Parmanto PhD, Matthew Scotch, and Sjarif Ahmad, (2005), A Framework for Designing a Healthcare Outcome Data Warehouse, the American Health Information Management Association

[15] Mary E. Morton, PhD, rhia, dan Susan Wiedenbeck, PhD, (2009), A Framework for Predicting EHR Adoption Attitudes: A Physician Survey, Health Information Management 6

[16] Chris Johnstone, MBChB, and Gerry McCartney, MBChB, (2010), A Patient Survey Assessing the Awareness and Acceptability of the Emergency Care Summary and its Consent Model, Health Information Management
[17] Ronaldo Parente, PhD, Ned Kock, PhD, and John Sonsini, (2004), An Analysis of the Implementation and Impact of Speech-Recognition Technology in the Healthcare Sector, Health Information Management 1;5

[18] Martin Pusic, MD, Dr J. Mark Ansermino, FFA, MMed, MSc, FRCPC, (2004), Clinical decision support systems, BCMJ, Vol. 46, No. 5

[19] Robert J. Campbell, EdD, (2005), Consumer Informatics: Elderly Persons and the Internet, Health Information Management

[20] Maria Skouroliakou, PhD; George Soloupis, MSc; Antonis Gounaris,MD; Antonia Charitou, MD; Petros apasarantopoulos; Sophia L. arkantonis, PhD; Christina Golna, LLM, MSc; and Kyriakos Souliotis, PhD, (2008), Data Analysis of the Benefits of an Electronic Registry of Information in a Neonatal Intensive Care Unit in Greece, Health

[21] Sorin Gudea, (2005), Data, Information, Knowledge: A Healthcare Enterprise Case Study, Health Information Management

[22] Amany A. Abdrbo, BSN, MSN, PhD; Jaclene A. Zauszniewski, PhD, RN-BC, FAAN; Christine A. Hudak, RN, PhD, CPHIMS; and Mary K. (2011), Anthony, PhD, RN, CS, Development and Testing of a Survey Instrument to Measure Benefits of a Nursing Information System, Health Information Management 1-15.

[23] Hatmoko Tri Arianto, Pemprograman Aplikasi Platform Terbuka Berbasis Xml Web (Studi Kasus: Kolaborasi Aplikasi Dan Pertukaran Data Kependudukan Dengan Catatan Medis), Fakultas Teknik, Universitas Diponegoro

[24] Hosizah, Electronic Health Record (Ehr) Atau Rekam Kesehatan Elektronik: Change In The Him Department,

[25] Eko Handoyo, Agung Budi Prasetijo, Fuad Noor Syamhariyanto, (2008), Aplikasi Sistem Informasi Rumah Sakit Berbasis Web Pada Sub-Sistem Farmasi Menggunakan Framework Prado, Universitas Diponegoro, Semarang

[26] Inne Gartina Husein , Anwar Hasdian Lubis (2011), Usulan Pengembangam Kebutuhan Medicls Record Berbasis Teknologi Web, Prosiding Conferensi Nasional ICTM Politeknik Telkom Bandun. 